\title{
Carnivore distributions across chaparral habitats exposed to wildfire and rural housing in southern California
}

\section{Authors: Paul Schuette, J. E. Diffendorfer, D. H. Deutschman, S. Tremor, and W. Spencer}

This is a postprint of an article that originally appeared in International Journal of Wildland Fire in May 2014.

Schuette, P. A., J. E. Diffendorfer, D. H. Deutschman, S. Tremor, and W. Spencer. "Carnivore distributions across chaparral habitats exposed to wildfire and rural housing in southern California." International Journal of Wildland Fire (2014). 


\title{
Carnivore distributions across chaparral habitats exposed to wildfire and rural housing in southern California
}

\author{
P. A. Schuette ${ }^{\mathrm{A}, \mathrm{B}, \mathrm{E}, \mathrm{F}}$, J. E. Diffendorfer ${ }^{\mathrm{C}}$, D. H. Deutschman ${ }^{\mathrm{A}}$, \\ S. Tremor ${ }^{\mathrm{B}}$ and W. Spencer ${ }^{\mathrm{D}}$ \\ A Department of Biology, San Diego State University, 5500 Campanile Drive, \\ San Diego, CA 92182, USA. \\ ${ }^{B}$ San Diego Natural History Museum, 1788 El Prado, Balboa Park, San Diego, CA 92101, USA. \\ ${ }^{\mathrm{C}}$ Geosciences and Environmental Change Science Center, US Geological Survey, \\ PO Box 25046, MS 980, Denver, CO 80225, USA. \\ ${ }^{D}$ Conservation Biology Institute, 815 Madison Avenue, San Diego, CA 92116, USA. \\ Eresent address: Department of Ecology, Montana State University, \\ 310 Lewis Hall, Bozeman, MT 59717, USA. \\ FCorresponding author. Email: paul@zambiacarnivores.org
}

\begin{abstract}
Chaparral and coastal sage scrub habitats in southern California support biologically diverse plant and animal communities. However, native plant and animal species within these shrubland systems are increasingly exposed to human-caused wildfires and an expansion of the human-wildland interface. Few data exist to evaluate the effects of fire and anthropogenic pressures on plant and animal communities found in these environments. This is particularly true for carnivore communities. To address this knowledge gap, we collected detection-non-detection data with motion-sensor cameras and track plots to measure carnivore occupancy patterns following a large, human-caused wildfire $\left(1134 \mathrm{~km}^{2}\right)$ in eastern San Diego County, California, USA, in 2003. Our focal species set included coyote (Canis latrans), gray fox (Urocyon cinereoargenteus), bobcat (Lynx rufus) and striped skunk (Mephitis mephitis). We evaluated the influence on species occupancies of the burned environment (burn edge, burn interior and unburned areas), proximity of rural homes, distance to riparian area and elevation. Gray fox occupancies were the highest overall, followed by striped skunk, coyote and bobcat. The three species considered as habitat and foraging generalists (gray fox, coyote, striped skunk) were common in all conditions. Occupancy patterns were consistent through time for all species except coyote, whose occupancies increased through time. In addition, environmental and anthropogenic variables had weak effects on all four species, and these responses were species-specific. Our results helped to describe a carnivore community exposed to frequent fire and rural human residences, and provide baseline data to inform fire management policy and wildlife management strategies in similar fire-prone ecosystems.
\end{abstract}

\section{Introduction}

Chaparral and coastal sage scrub habitats support a diverse array of organisms and a high number of endemic species (Dobson et al. 1997). However, these shrubland habitats are exposed to increasing frequencies of wildfire due to rapid human population growth and the expansion of the wildlandurban interface (Keeley et al. 1999; Keeley and Fotheringham 2001; Syphard et al. 2009). These anthropogenic pressures have contributed to habitat loss, fragmentation and fire-mediated exotic invasions, which have degraded the native biological diversity of southern California (D'Antonio and Vitousek 1992; Keeley et al. 2003; Crooks et al. 2004; Diffendorfer et al. 2007). Information on how different taxa respond to increasing rates of wildfire and other anthropogenic pressures will help inform management decision making and policy in chaparral habitats.

In the shrublands of southern California, several decades of research has been carried out on plant, bird and small mammal responses to habitat loss, fragmentation and fire (Keeley and Zedler 1978; Soulé et al. 1988; Sauvajot et al. 1998; Crooks et al. 2004; Diffendorfer et al. 2012). Studies in areas between Los Angeles and San Diego have evaluated the influence of urban edges and habitat fragmentation on the native carnivore community, which includes coyote (Canis latrans), gray fox (Urocyon cinereoargenteus), bobcat (Lynx rufus) and striped skunk (Mephitis mephitis) (Crooks and Soulé 1999; Fedriani et al. 2001; Riley et al. 2003; Markovchick-Nicholls et al. 2008), yet we know very little about their response to wildfire 
in these areas (Lawrence 1966; Fisher and Wilkinson 2005). In fact, only a few studies worldwide have described carnivore responses to fire. Prior research has documented foraging patterns in grizzly bears (Ursus arctos horribilis) (Blanchard and Knight 1990), gray wolves (Canis lupus) (Ballard et al. 2000) and Florida panthers (Puma concolor coryi) (Dees et al. 2001), and habitat use in black bears (Ursus americanus) (Cunningham et al. 2003). Only two published studies of which we are aware have examined the response to fire by carnivore species that occur in southern California (Cunningham et al. 2006; Borchert 2012). As wildfire frequency is correlated with human population density in southern California (Keeley and Fotheringham 2001), it is important that we address this knowledge gap on carnivores and integrate the information into future management decisions.

From 25 October to 2 November 2003, the Cedar fire burned $1134 \mathrm{~km}^{2}$ (28 0278 acres) of chaparral, coastal sage scrub and pine forest, making it the largest recorded fire in California's history (CDF 2003); though the 2007 wildfires were comparable in scope. In many areas, the Cedar fire burned to the edge of suburban residential areas and into rural housing areas. Although fire severity varied across the burned landscape, little aboveground vegetation remained, except in protected patches in drainages and near rock outcrops. Studies of vegetation in the Cedar fire (Keeley et al. 2008; Diffendorfer et al. 2012) reported a range of fire severity, but most areas were entirely denuded of shrub cover with the exception of sites near riparian areas or rock outcroppings, which had more shrub cover than open areas. Fire severity had a small effect on post-fire vegetation dynamics (Keeley et al. 2008) and vegetation cover in burned locations varied according to rainfall (Diffendorfer et al. 2012). Herbaceous vegetation cover peaked in the spring of 2005 following rainfall but then declined through time as shrub cover increased from 2004 to 2006 . Small mammals - the prey base for many carnivores - were present in burned locations but their relative abundances differed between burned and unburned plots, primarily due to the absence or low abundances of species associated with shrub cover. In general, small mammal abundances increased on burned plots between 2004 and 2007 (Diffendorfer et al. 2012).

Following the fire, we examined carnivore distributions in relation to environmental and anthropogenic variables in areas within the Cedar fire perimeter and nearby unburned areas. Specifically, our intent was to evaluate spatial and temporal patterns of four behaviourally diverse carnivore species that are common in chaparral shrublands: coyote, a highly mobile, habitat and foraging generalist (Kamler and Gipson 2000; Grinder and Krausman 2001); gray fox, a foraging generalist that prefers dense habitats (Fuller 1978; Hockman and Chapman 1983); striped skunk, a habitat and foraging generalist (Dijak and Thompson 2000; Ng et al. 2004) and bobcat, a cryptic, obligate predator that prefers dense habitats (Litvaitis et al. 1986; Delibes et al. 1997).

Our primary objectives were to (1) document occupancy patterns of four medium-sized carnivore species that are native to chaparral shrublands and (2) evaluate whether occupancies changed through time across sites that varied in their combination of exposure to burn status, rural human residences and other environmental attributes. In our study, rural homes were typified as suburban dwellings with small areas of cleared land. Agriculture around homes was not present, given the high topographic relief, boulders and arid conditions. Post-fire patterns could be caused by species' responses to unburned habitat (preference or avoidance) and their ability to disperse into burned areas, assuming they either died or fled during or soon after the fire. We examined the following specific hypotheses based on behavioural attributes for each species: (1) coyote would be common across all sites, regardless of burn status, rural homes and environmental factors, because of their high vagility and their generalist foraging patterns; (2) striped skunk occupancies would be low in the burn interior because of their lower vagility than coyotes, but they would exhibit high occupancies across all other areas because of their generalist foraging patterns; (3) gray fox occupancies would be low in the burn interior because they also have lower vagility than coyotes, but their occupancies would be high in unburned areas where dense cover exists and moderate in burned edges, and these patterns would be unrelated to rural homes and environmental factors because of their generalist foraging patterns and (4) bobcat occupancies would be high in unburned areas where dense cover is available, and they would avoid areas in close proximity to rural homes.

\section{Materials and methods}

\section{Study area}

From January 2006 to June 2007, we used motion-sensor cameras and track plots to conduct detection-non-detection surveys in the Cleveland National Forest and Cuyamaca Rancho State Park in eastern San Diego County, California, USA (Fig. 1). All sites were located in chaparral habitat composed primarily of burned or unburned stands of Adenostoma fasciculatum, Artemisia californica and Arctostaphylos spp. The climate is arid with an average rainfall of $400 \mathrm{~mm}$ per year and average minimum and maximum temperature range of $10.1-24.8^{\circ} \mathrm{C}$ (50.2-76.6 ${ }^{\circ} \mathrm{F}$ ) (Western Regional Climate Center 2011).

\section{Sampling design}

We selected 31 sites spaced $\geq 2 \mathrm{~km}$ apart and spanning areas that varied in their burn status, distance from the fire perimeter, proximity to rural homes, elevation and distance to riparian area. We classified sites based on their burn status as follows: (1) burn edge, areas that burned in the Cedar fire and were $<4 \mathrm{~km}$ from the fire perimeter (11 sites); (2) burn interior, areas that burned in the Cedar fire and were $>4 \mathrm{~km}$ from the fire perimeter (10 sites) and (3) unburned, areas that did not burn in the Cedar fire and had not burned in $>20$ years ( 10 sites) (Fig. 1). We used burn status as a measure of habitat, based on the assumption that burn status would alter vegetation structure and density in a manner that affects carnivore movement, visibility and protective cover. Burned sites consisted of dense stands of mature chaparral shrubs (high protective cover, low visibility and limited movement), and unburned sites were composed of seedlings and resprouting shrubs, which provided less habitat structure and density (less protective cover, higher visibility and greater ease of movement) (see Fig. S1 of the Supplementary material for representative site photographs). Sites were also categorised by their proximity to rural homes as follows: (1) low-density rural, sites with $<5$ houses within a $1-\mathrm{km}$ radius (18 sites) and 


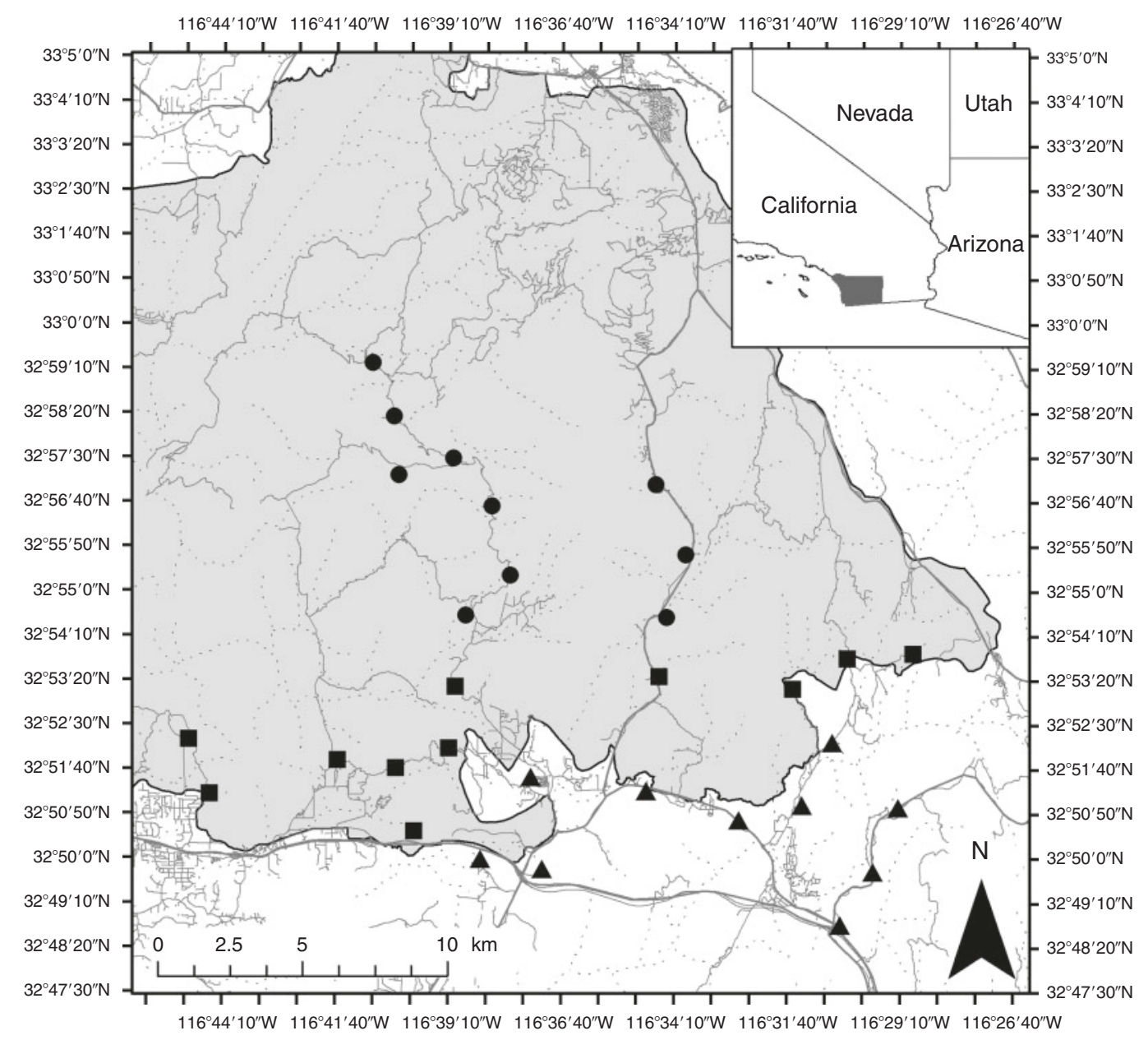

Fig. 1. Focal study area in chaparral habitats in east-central San Diego County, California, USA. Detection-non-detection surveys were implemented at sites inside the Cedar fire perimeter (grey area), including sites within areas classified as burn edge (squares) and burn interior (circles), and nearby unburned areas (triangles). Sites were located $>200 \mathrm{~m}$ from paved roads (thick black lines) and low-use ( $<10$ vehicles per day) and unpaved roads (thin black lines), and at variable distances from riparian areas (stippled lines). Despite the availability of roads, site selection was limited due to public accessibility, permissions from local agencies and closures from fire hazards. The inset shows the location of the Cedar fire and our focal study site in San Diego County, California.

(2) moderate-density rural, sites with $>10$ houses within a 1-km radius (13 sites). Sites ranged in distance to riparian area $(0-1.4 \mathrm{~km})$ and elevation $(765-1577 \mathrm{~m})$. In general, lower elevation chaparral habitats were dominated by the typical local chaparral shrub species and higher elevation habitats consisted of these species plus a mix of oak shrubs (Quercus spp.) and conifers. All sites were located in the south-eastern section of the Cedar fire. Sites were limited to public lands where agencies allowed us to work and where we had road access, and to areas that were not closed because of post-fire hazards. All sites were located $>200 \mathrm{~m}$ from paved or rarely used roads $(<10$ vehicles per day) in areas where the potential for human disturbance at a camera station or track plot was minimal.

Each site contained three sampling stations consisting of one motion-activated, infrared camera (Game-Vu, Nature Vision, Baxter, Minnesota, USA) and two track plots. All sampling stations were spaced $100 \mathrm{~m}$ from each other. At camera stations, one camera was set $\sim 20 \mathrm{~cm}$ from the ground with the focal area fixed on a scent post $2 \mathrm{~m}$ from the camera. Track plots consisted of a $1-\mathrm{m}^{2}$ area of smoothed gypsum powder with a scent post in the middle (Linhart and Knowlton 1975; Crooks 2002). Scent posts for both camera stations and track plots consisted of a $30-\mathrm{cm}$ metal tent stake wrapped with a pipe cleaner around the top portion that was coated with a scent lure suitable for multiple North American carnivore species (Carman's Pro's Choice, Sterling Fur and Tool Co., Ohio).

We surveyed each site for 6 nights three times per year (five times total) during the winter (January 2006, 2007), spring (May-June 2006, 2007) and autumn (August-September 2006). We visited sites every 3 days ( 2 nights) to record camera images and tracks to the species level, ensure cameras were operating properly (e.g. check battery power), smooth gypsum powder at track plots and reapply scent lure. We surveyed one-third of all burn edge, burn interior and unburned sites during each 6-night survey. Thus, it required 18 nights to survey all 31 sites each season. We considered each 6-night survey the primary 
sampling period that consisted of three, 2-night secondary sampling occasions.

\section{Data analysis}

We analysed detection-non-detection data with single-species, multi-season occupancy models (MacKenzie et al. 2006). This technique provides unbiased estimates of species occupancies by accounting for detection probability and allows parameters to vary as a function of environmental variables, site characteristics and time. Multi-season occupancy models estimate the probability a species is present at a site during the first primary sampling period (occupancy, $\hat{\psi}_{1}$ ), the probability a species will be detected at a site given it is present $(\hat{p})$ and the probability of local colonisation $(\hat{\gamma})$ and extinction $(\hat{\varepsilon})$ through time (MacKenzie et al. 2006). We examined each parameter in relation to variables we hypothesised would influence species occupancy patterns. We evaluated the influence of three environmental variables (burn status, distance to riparian area, elevation) and one anthropogenic variable (rural homes) on species occupancy. We also included models where the occupancy parameter was held constant (i.e. uninfluenced by any of our environmental or anthropogenic variables). We examined whether species occupancies were constant or changing through time by including the primary sampling period as a potential covariate affecting local colonisation and extinction. Last, we examined whether species detection probabilities were constant or were affected by environmental conditions (burn status) or rural homes. We also accounted for the possibility that detection probability may change within a primary sampling period (i.e. a 6-night period) by including secondary sampling occasions as a potential covariate influencing detection probability. Overall, our a priori model set included 128 candidate models we hypothesised may explain carnivore occupancies and changes in occupancies through time (i.e. post-fire recovery) (see Table S1 of the Supplementary material). We examined the fit of each model for each species using the UNMARKED package in R (R Development Core Team 2010; Chandler et al. 2011). We compared support for models using Akaike's Information Criterion (AIC), delta AIC ( $\triangle \mathrm{AIC})$, and AIC weights (AIC w) (Burnham and Anderson 2002; R Development Core Team 2010). We present model-averaged estimates of each parameter value for models where $\Delta \mathrm{AIC} \leq 4$ (Burnham and Anderson 2002).

Prior to our analysis, we examined whether our continuous independent variables (elevation, riparian area) were correlated and did not find a strong relationship $(r=-0.21)$. We used McNemar's test of symmetry (Agresti 1990) to test for sampling bias among the track plots and the cameras at each site. This comparison revealed that track plots and the camera at each site were not independent samples $(P>0.05$ for all pairwise comparisons) and thus it was appropriate to pool data from the three scent stations at each site during each secondary sampling occasion. Interestingly, coyotes were detected more often at each track plot (61 detections at track plot 1 and 56 detections at track plot 2) than at cameras (39 detections) (track plot $1 v$. camera, $\chi^{2}=5.13, P=0.024$; (track plot $2 v$. camera, $\chi^{2}=$ 3.32, $P=0.068$ ), whereas bobcats showed the opposite pattern (6 detections at track plot 1, 4 detections at track plot 2 , 23 camera detections $)\left(\chi^{2}=8.83, P=0.003 ; \quad \chi^{2}=15.43\right.$,
$P=<0.001)$. These results support previously observed patterns for these species using similar data collection strategies (Windberg 1996; Harris and Knowlton 2001).

\section{Results}

We conducted surveys on 451 of 465 (97\%) possible sampling occasions (31 sites $\times$ five primary sampling periods $\times$ three secondary occasions). On the other 14 occasions, inclement weather or other logistical constraints prevented us from visiting a site.

Overall, we detected gray fox most often, followed by coyote, striped skunk and bobcat (Table 1). Raccoon (Procyon lotor), opossum (Didelphis virginiana), mule deer (Odocoileus hemionus), rabbit (Sylvilagus spp.), domestic dogs and cats, and a variety of rodents, birds and lizards were also detected occasionally, but were not considered in this analysis because of the low number of detections. Estimated detection probability was highest for gray fox, followed by coyote, striped skunk and bobcat. For gray fox and striped skunk, detection probability was generally constant across space and time (Table 2). Coyote detection probability was influenced primarily by proximity to rural homes (cumulative AIC $w=0.31$ ) and burn status (cumulative AIC $w=0.24)$. Bobcats followed a similar pattern, with their detection probability influenced primarily by burn status (cumulative AIC $w=0.15$ ) and proximity to rural homes (cumulative AIC $w=0.14$ ) (Tables 1, 2).

Model selection procedures indicated constant levels of occupancy per species with some influences of environmental conditions. For all species but bobcat, models that included constant occupancies across sites were well supported (i.e. $\triangle \mathrm{AIC}<2$ and high AIC $w$ ) (Table 2) given the data and the candidate model set, a pattern that indicates these generalist species are common in this post-fire environment. However, we observed substantial differences in occupancy across species. Gray fox had the highest occupancy, followed by striped skunk, coyote and possibly bobcat, although inferences for this species are limited because of a low number of detections (Fig. 2, grey horizontal bands). Though the generalist species were common in this landscape, all four species were influenced to some degree by anthropogenic and environmental conditions (Table 2). In general, burn status had the most substantial influence (based on cumulative AIC $w$ ) on gray fox and striped skunk occupancies. Model-averaged estimates of gray fox occupancies were slightly higher in the burn interior that in the burn edge and unburned areas (Fig. 2a). This pattern does not support our hypothesis of high gray fox occupancy in the burn edge and unburned areas. In contrast, our hypothesis regarding striped skunk response to the fire was partially supported. Striped skunk occupancy was higher in areas within the burn edge (Fig. $2 b$ ) than in the burned interior and unburned areas. Though proximity to rural homes, elevation, and distance to riparian areas received support in our model-selection procedures, model-averaged occupancy estimates $( \pm$ s.e. $)$ for these species did not show any strong patterns.

Burn status appeared in well-supported models for coyote and bobcat, but model-averaged estimates of occupancies $( \pm$ s.e.) for these species were similar across burn status types. Of the variables we considered, only proximity to rural homes had an apparent effect on coyote occupancy. Coyote occupancy was higher in areas that had few or no rural homes $(<5$ homes 
within $1 \mathrm{~km}$ ) compared with areas with moderate levels of rural homes ( $>10$ homes within $1 \mathrm{~km})$. However, this effect was weak, and it was only apparent in the burn interior (Fig. 2c). Estimated occupancies of bobcat were weakly associated with elevation (Fig. 2d). However, the overall low number of detections for bobcats limits our ability to make inferences. We attribute our low sample sizes for bobcat primarily to the difficulty of collecting data for cryptic carnivores at scent stations or their overall low abundance in our focal study area (Conner et al. 1983).

Observed gray fox, striped skunk and bobcat occupancy patterns were consistent across our five sampling periods

Table 1. Total number of detections per species and model-averaged estimates of detection probability ( $\hat{p})$ and standard error (s.e.) using the covariate that received the most overall support (based on cumulative Akaike Information Criterion (AIC) weights) per species

\begin{tabular}{|c|c|c|c|c|}
\hline Species & Detections & Variable influencing $\hat{p}$ & $\hat{p}$ & s.e. \\
\hline Gray fox & 215 & Constant & 0.55 & 0.04 \\
\hline \multirow[t]{3}{*}{ Coyote } & 129 & Burn $_{\text {(unburned) }}$ & 0.51 & 0.06 \\
\hline & & Burn $_{(\text {edge })}$ & 0.54 & 0.05 \\
\hline & & Burn $_{\text {(interior) }}$ & 0.38 & 0.16 \\
\hline Striped skunk & 44 & Constant & 0.22 & 0.06 \\
\hline \multirow[t]{2}{*}{ Bobcat } & 30 & Residential $_{\text {(moderate) }}$ & 0.07 & 0.03 \\
\hline & & Residential $_{(\text {low })}$ & 0.11 & 0.04 \\
\hline
\end{tabular}

(Table 2). For these three species, models where the local colonisation and extinction parameters were held constant were well supported. The lack of response by these species suggests that despite changes in vegetation structure and potential prey in the burned areas (Diffendorfer et al. 2012), these species were not responding to changes in the post-fire environment during the period we studied. In contrast, coyote occupancy patterns did change through time, as shown by the number of well-supported models where primary sampling period is associated with local colonisation and extinction (Table 2). Estimates of local colonisation and extinction indicate coyote occupancy patterns fluctuated across primary sampling periods, particularly within the first two to three sampling periods (Fig. 3). Our data indicate that despite coyote being only weakly associated with the environmental and anthropogenic variables, their overall occupancy patterns (regardless of site attributes) increased through time (Fig. 4). Whether this pattern represents coyotes recolonising the region (burned and unburned) after the fire and settling into new territories or another mechanism is uncertain, but our data indicate a peak in coyote occupancy across all environmental and anthropogenic conditions approximately 34 months after the Cedar fire.

\section{Discussion}

Despite the vast size of the area burned by the Cedar fire and its effects on habitat structure, carnivore occupancy was generally

Table 2. Model selection output for models where $\Delta \mathrm{AIC} \leq \mathbf{2}$

The occupancy parameter $(\hat{\psi})$ could be associated with rural residences (two levels), burn status (three levels), riparian area (0-1.5 km) or elevation ( $700-$ $1600 \mathrm{~m}$ ). The colonisation $(\hat{\gamma})$ and extinction $(\hat{\varepsilon})$ parameters could be constant $(1)$ or changing through time (primary sampling periods). Detection probability $(\hat{p})$ could be either constant (1), or associated with rural residences (two levels), burn status (three levels) or secondary sampling occasions

\begin{tabular}{|c|c|c|c|c|c|c|c|c|}
\hline Species & $\hat{\psi}$ & $\hat{\gamma}$ & $\hat{\varepsilon}$ & $\hat{p}$ & $\begin{array}{c}\text { Number } \\
\text { of parameters }\end{array}$ & AIC & $\Delta \mathrm{AIC}$ & $\mathrm{AIC} w$ \\
\hline \multirow[t]{7}{*}{ Coyote } & 1 & primary & primary & burn & 12 & 489.82 & 0.00 & 0.13 \\
\hline & residential + burn + riparian + elevation & primary & primary & residential & 16 & 490.20 & 0.39 & 0.11 \\
\hline & residential + burn + riparian + elevation & 1 & 1 & residential & 10 & 490.85 & 1.03 & 0.08 \\
\hline & residential & primary & primary & burn & 13 & 490.90 & 1.08 & 0.08 \\
\hline & residential + burn + riparian & primary & primary & residential & 15 & 491.58 & 1.76 & 0.06 \\
\hline & elevation & primary & primary & burn & 13 & 491.70 & 1.88 & 0.05 \\
\hline & riparian & primary & primary & burn & 13 & 491.82 & 2.00 & 0.05 \\
\hline \multirow[t]{6}{*}{ Gray fox } & 1 & 1 & 1 & 1 & 4 & 592.68 & 0.00 & 0.12 \\
\hline & burn & 1 & 1 & 1 & 6 & 593.69 & 1.01 & 0.07 \\
\hline & residential & 1 & 1 & 1 & 5 & 594.45 & 1.77 & 0.05 \\
\hline & 1 & 1 & 1 & residential & 5 & 594.59 & 1.90 & 0.05 \\
\hline & elevation & 1 & 1 & 1 & 5 & 594.67 & 1.99 & 0.04 \\
\hline & riparian & 1 & 1 & 1 & 5 & 594.68 & 2.00 & 0.04 \\
\hline \multirow[t]{4}{*}{ Bobcat } & riparian + elevation + burn & 1 & 1 & residential & 9 & 212.12 & 0.00 & 0.15 \\
\hline & residential + riparian & 1 & 1 & burn & 8 & 213.22 & 1.10 & 0.08 \\
\hline & residential + elevation & 1 & 1 & burn & 8 & 213.89 & 1.77 & 0.06 \\
\hline & burn + elevation & 1 & 1 & secondary & 9 & 213.89 & 1.78 & 0.06 \\
\hline \multirow[t]{8}{*}{ Striped skunk } & burn & 1 & 1 & 1 & 6 & 282.37 & 0.00 & 0.11 \\
\hline & 1 & 1 & 1 & 1 & 4 & 283.31 & 0.94 & 0.07 \\
\hline & burn + riparian & 1 & 1 & 1 & 7 & 283.97 & 1.60 & 0.05 \\
\hline & burn + elevation & 1 & 1 & 1 & 7 & 284.03 & 1.66 & 0.05 \\
\hline & burn & 1 & 1 & residential & 7 & 284.19 & 1.82 & 0.04 \\
\hline & riparian & 1 & 1 & 1 & 5 & 284.27 & 1.90 & 0.04 \\
\hline & residential + burn & 1 & 1 & 1 & 7 & 284.30 & 1.93 & 0.04 \\
\hline & elevation & 1 & 1 & 1 & 5 & 284.33 & 1.96 & 0.04 \\
\hline
\end{tabular}



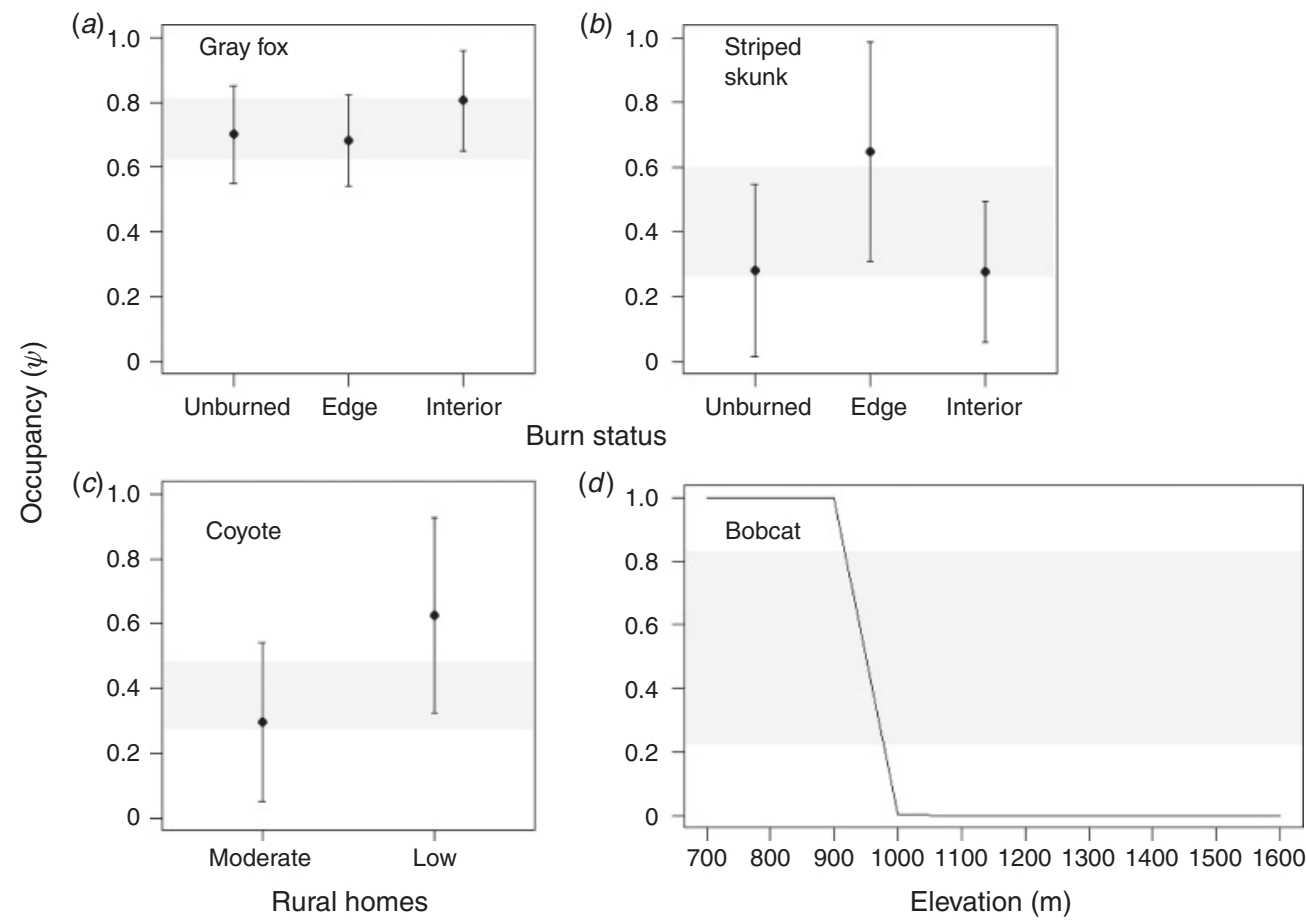

Fig. 2. Model-averaged occupancy estimates ( \pm s.e.) (models with $\Delta$ AIC $\leq 4)$ for $(a)$ gray fox, $(b)$ striped skunk, $(c)$ coyote and $(d)$ bobcat. Estimated occupancy ( \pm s.e.) with the occupancy parameter held constant (i.e. no covariates) are shown in grey bands, which can be used to compare overall occupancy rates across species. Estimates from the most influential covariate for each species are shown with black points and standard errors. For coyote, the effect of rural homes was only apparent in the burn interior. Estimated standard errors for bobcat were close to zero and are not shown.

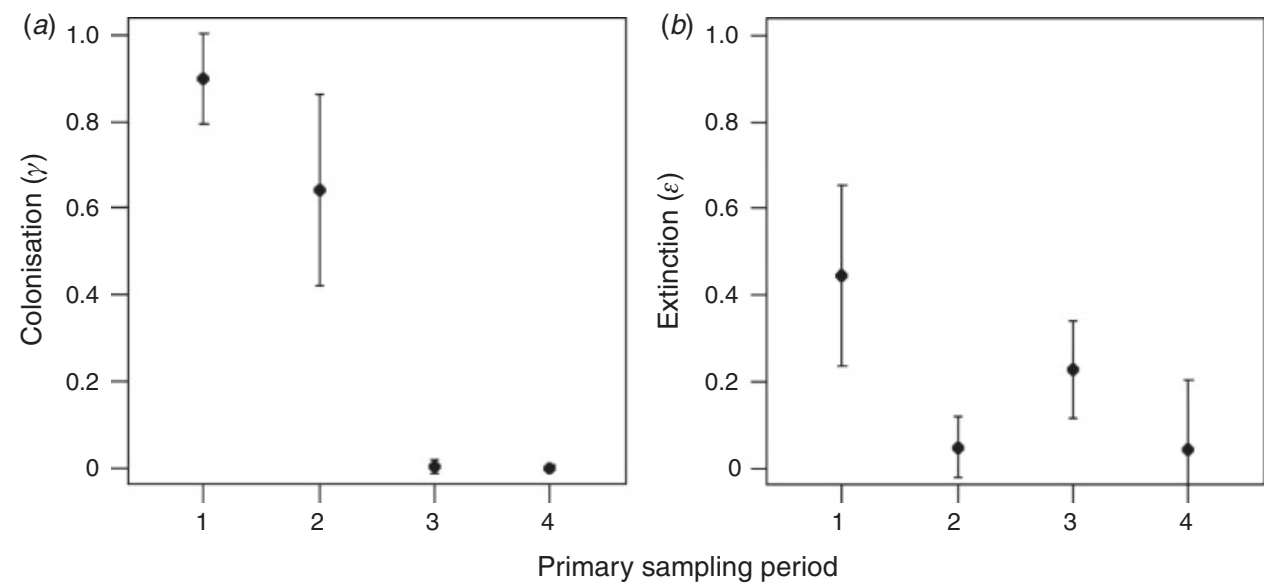

Fig. 3. Changes in coyote occupancy through time (primary sampling period). Estimated patterns of local (a) colonisation and $(b)$ extinction ( \pm s.e.) for a model where occupancy was constant across space because of the low influence of anthropogenic or environmental variables on this generalist species. Coyote was the only species whose occupancy changed through time.

constant across space and fire effects were mild, on par with rural housing effects, proximity to riparian areas and elevation gradients. Observed species-specific effects, though weak, do provide baseline information that documents how three generalist carnivores and one specialist carnivore respond to the post-fire environment. These results address a gap in our understanding of carnivore ecology in chaparral habitats of southern California.

\section{Burn status}

Burn status appeared in well-supported models in all species, but the effects were most apparent in gray fox, striped skunk 

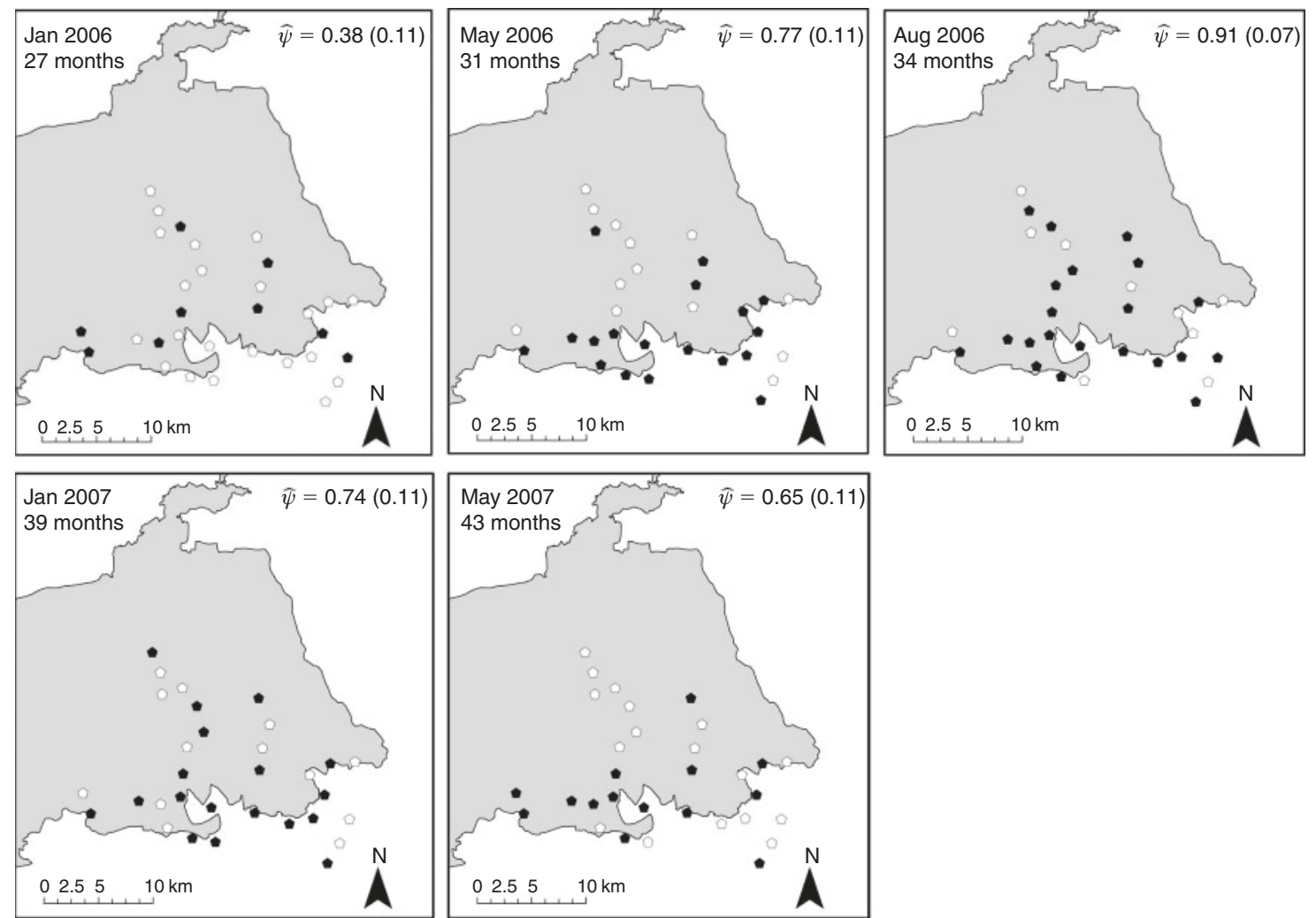

Fig. 4. Model-averaged estimates of coyote occupancy $(\hat{\psi})$ (s.e.) over 27-43 months following the Cedar fire in San Diego County, California (grey area). Black pentagons represent sites where a coyote was detected and white pentagons represent sites where a coyote was not detected during each primary sampling period.

and to a lesser extent, coyote. Slightly higher gray fox occupancy in the burn interior was contrary to our expectation, and could be explained by several possible mechanisms. First, gray fox may have found refuge during the Cedar fire in unburned patches or rocky crevices that did not require recolonisation. Alternatively, gray fox occupancy may have declined during and immediately following the Cedar fire, but our sampling methods failed to detect these changes beginning 27 months after the fire. Though we do not have data to distinguish between these alternatives, slightly higher gray fox occupancy in the burn interior suggests that the early successional stages of recovery in this area provided a suitable and available niche for these species to exploit, possibly due to high prey availability (Blanchard and Knight 1990; Dees et al. 2001; Cunningham et al. 2003). An independent study of the small mammal community following the Cedar fire indicated that several potential prey species, including the California pocket mouse (Chaetodipus spp.) and cactus mouse (Peromyscus eremicus), had high population growth rates in the burn interior (Diffendorfer et al. 2012). Thus, high population growth rates of potential prey species may help explain observed gray fox occupancy patterns in the burn interior. High prey availability in the burn interior may have also influenced coyote, which were weakly associated with the burn interior, particularly in areas where rural homes were rare or nonexistent (Fig. 2c). High striped skunk occupancies in the burn edge environment support our expectations for this generalist species. It is possible this stage of successional recovery or this edge habitat provided suitable conditions for striped skunk but not for other species to occur at high rates. The burn edge may have allowed striped skunk to move freely between burned and unburned habitats, potentially seeking food sources in the burned area, but resting or bedding down in the more densely vegetated unburned habitats (Blanchard and Knight 1990). However, despite observed differences to the burned environment, the lack of temporal dynamics in species occupancy (except in coyote) indicate any changes likely took place at a slower rate than we could detect or occurred before the start of our study.

\section{Rural housing}

Despite the appearance of rural housing in well-supported models of all focal species, only coyote showed any evidence of a difference in occupancy between areas classified as containing moderate and low densities of rural homes. This result seemingly contrasts with several studies that have reported that coyotes are tolerant of, or even prefer, residential areas (Fedriani et al. 2001; Grinder and Krausman 2001; Riley et al. 2003). However, our study was in rural areas where even our classification of moderate human residences is far less than the urban areas considered in prior studies in southern California. The lack 
of a strong response by co-occurring carnivores indicates that the current level of rural human residences in our focal study does not have a strong limiting effect on species occupancies, except in coyote.

\section{Elevation and riparian areas}

Model output indicated elevation and distance to riparian areas affected species occupancies, but these effects were weak. We expected occupancy patterns to vary across these gradients, particularly in gray fox and bobcat (because of their previously described preference for dense cover, Fuller 1978; Fritzell 1987; Farias 2005), which were typically more common at high elevations and near riparian areas. However, only bobcat occupancies were associated with elevation, and followed a trend in the opposite direction of our expectation.

Overall, our results agree with the classification of these species as habitat and foraging generalists that occur at variable rates across this landscape. This first baseline study indicates our focal set of carnivore species seems to be resilient to fire and can quickly begin utilising successional habitat. However, coyote exhibited a unique response to the post-fire environment that may provide additional insights into patterns of carnivore recolonisation. In general, coyote occupancy increased across the study area in a manner that was not directly attributable to the variables we considered. This pattern could indicate that both burned areas and unburned areas adjacent to the fire $(<10 \mathrm{~km}$ from fire perimeter) may have experienced an overall decline in the coyote population, or that coyotes dispersed from this region following the fire and slowly recolonised and established new territories (Harrison 1992). Alternatively, this could present a sampling bias, in which the scent lure provided an attractant to coyotes, which was then frequently visited for scent-marking and territoriality purposes (Allen et al. 1999). If so, then high occupancy rates could represent a learned response in which coyotes were cautious to investigate scent stations during the first sampling period, but they started to investigate these novel visual (track plot, camera) or olfactory stimuli (scent lure) through time (Windberg 1996; Harris and Knowlton 2001). To test for this possibility, we conducted a post hoc test to determine whether detection probability increased through time. We did this by reanalysing the coyote data, but we included models in our model set in which detection probability could vary by primary sampling period (model set increased from 128 to 144 models). Using this test, we found no support for models with primary sampling period influencing the detection probability parameter $(\Delta$ AIC $>4)$. Thus, we consider observed coyote occupancy an ecological response rather than a methodological bias.

\section{Carnivore interactions}

We did not explicitly test competitive interactions within our focal set of carnivores. However, species-specific responses to burn status and rural housing support patterns of spatial partitioning that have been previously documented in this carnivore community (Fedriani et al. 2000; Neale and Sacks 2001; Farias 2005). For example, gray fox occurred at slightly higher rates in the burn interior than any of the other focal species. This response may be related to habitat and foraging opportunities, but might also be related to avoidance of coyotes and bobcats (competitively dominant to gray fox), or exploitation of habitat and foraging opportunities not exploited by these two species (Henke and Bryant 1999; Neale and Sacks 2001; Farias 2005). Although we do not have data to test these hypotheses, observed differences among species suggests competitive avoidance or displacement may be a factor influencing carnivore spatial patterns. Further detailed investigations of carnivore interactions through behavioural tracking of radio-collared individuals would help to clarify the mechanisms associated with observed spatial patterns.

In conclusion, our study revealed that four carnivores are common in the post-fire environment, at least in a period of time 27-43 months after the Cedar fire. We attribute this pattern to behavioural plasticity among generalist carnivores, which probably allows them to adjust to variable conditions in the burned environment. This pattern was particularly evident in gray fox, striped skunk and possibly bobcat. We encourage future researchers to investigate coyote (and other carnivores capable of moving large distances) to evaluate the mechanisms behind spatial and temporal changes in occupancy in the postfire environment.

\section{Acknowledgements}

We thank the California Department of Fish and Game, the US Forest Service and California State Parks for permission to conduct this research. We appreciate the assistance of D. Hogan, G. Fleming, D. Morin, and A. Soto-Centeno in the field. This study was supported by a grant to the Forest Service Pacific Southwest Research Station, San Diego Natural History Museum and Conservation Biology Institute from the Joint Fire Science Program (number 042194). We appreciate the comments and suggestions made by Steve Garman and several anonymous reviewers that improved the final version of this manuscript. Any use of trade, product or firm names is for descriptive purposes only and does not imply endorsement by the US Government.

\section{References}

Agresti A (1990) 'Categorical Data Analysis.' (Wiley-Interscience: New York)

Allen JJ, Bekoff M, Crabtree RL (1999) An observational study of coyote (Canis latrans) scent-marking and territoriality in Yellowstone National Park. Ethology 105(4), 289-302. doi:10.1046/J.14390310.1999.00397.X

Ballard WB, Krausman PR, Boe S, Cunningham SC, Whitlaw HA (2000) Short-term response of gray wolves, Canis lupis, to wildfire in northwestern Alaska. Canadian Field Naturalist 114(2), 241-247.

Blanchard BM, Knight RR (1990) Reactions of grizzly bears, Ursus arctos horribilis, to wildfire in Yellowstone National Park, Wyoming. Canadian Field Naturalist 104(4), 592-594.

Borchert MI (2012) Mammalian carnivore use of a high-severity burn in conifer forests in the San Bernardino mountains of southern California, USA. Hystrix 23(2), 1022-1028.

Burnham KP, Anderson DR (2002) 'Model Selection and Multimodel Inference: a Practical Information-theoretic Approach.' (Springer: New York)

CDF (2003) California Department of Forestry \& Fire Protection: Cedar fire incident information. Available at http://www.fire.ca.gov/cdf/incidents/ Cedar\%20Fire_120/incident_info.html [Verified 1 March 2014]

Chandler RB, Royle JA, King DI (2011) Inference about density and temporary emigration in unmarked populations. Ecology 92, 1429-1435. doi:10.1890/10-2433.1 
Conner MC, Labisky RF, Progulske DR, Jr (1983) Scent-station indices as measures of population abundance for bobcats, raccoons, gray foxes, and opossums. Wildlife Society Bulletin 11(2), 146-152.

Crooks KR (2002) Relative sensitivities of mammalian carnivores to habitat fragmentation. Conservation Biology 16(2), 488-502. doi:10.1046/ J.1523-1739.2002.00386.X

Crooks KR, Soulé ME (1999) Mesopredator release and avifaunal extinctions in a fragmented system. Nature 400(6744), 563-566. doi:10.1038/ 23028

Crooks KR, Suarez AV, Bolger DT (2004) Avian assemblages along a gradient of urbanization in a highly fragmented landscape. Biological Conservation 115(3), 451-462. doi:10.1016/S0006-3207(03)00162-9

Cunningham SC, Ballard WB, Monroe LM, Rabe MJ, Bristow KD (2003) Black bear habitat use in burned and unburned areas, central Arizona. Wildlife Society Bulletin 31(3), 786-792.

Cunningham SC, Kirkendall LB, Ballard WB (2006) Gray fox and coyote abundance and diet responses after a wildfire in central Arizona. Western North American Naturalist 66(2), 169-180. doi:10.3398/1527-0904 (2006)66[169:GFACAA]2.0.CO;2

D'Antonio CM, Vitousek PM (1992) Biological invasions by exotic frasses, the grass/fire cycle, and global change. Annual Review of Ecology and Systematics 23, 63-87.

Dees CS, Clark JD, Manen FTV (2001) Florida panther habitat use in response to prescribed fire. The Journal of Wildlife Management 65(1), 141-147. doi:10.2307/3803287

Delibes M, Blazquez MC, Rodriguez-Estrella R, Zapata SC (1997) Seasonal food habits of bobcats (Lynx rufus) in subtropical Baja California Sur, Mexico. Canadian Journal of Zoology 75(3), 478-483. doi:10.1139/Z97-058

Diffendorfer JE, Fleming GM, Duggan JM, Chapman RE, Rahn ME, Mitrovich MJ, Fisher RN (2007) Developing terrestrial, multi-taxon indices of biological integrity: an example from coastal sage scrub. Biological Conservation 140(1-2), 130-141. doi:10.1016/J.BIOCON. 2007.08.005

Diffendorfer J, Fleming GM, Tremor S, Spencer W, Beyers JL (2012) The role of fire severity, distance from fire perimeter and vegetation on post-fire recovery of small-mammal communities in chaparral. International Journal of Wildland Fire 21, 436-448. doi:10.1071/ WF10060

Dijak WD, Thompson FR III (2000) Landscape and edge effects on the distribution of mammalian predators in Missouri. The Journal of Wildlife Management 64(1), 209-216. doi:10.2307/3802992

Dobson AP, Rodriguez JP, Roberts WM, Wilcove DS (1997) Geographic distribution of endangered species in the United States. Science 275(5299), 550-553. doi:10.1126/SCIENCE.275.5299.550

Farias V (2005) Survival and cause-specific mortality of gray foxes. Journal of Zoology 266, 249-254. doi:10.1017/S0952836905006850

Fedriani JM, Fuller TK, Sauvajot RM, York EC (2000) Competition and intraguild predation among three sympatric carnivores. Oecologia 125(2), 258-270. doi:10.1007/S004420000448

Fedriani JM, Fuller TK, Sauvajot RM (2001) Does availability of anthropogenic food enhance densities of omnivorous mammals? An example with coyotes in southern California. Ecography 24(3), 325-331.

Fisher JT, Wilkinson L (2005) The response of mammals to forest fire and timber harvest in the North American boreal forest. Mammal Review 35(1), 51-81. doi:10.1111/J.1365-2907.2005.00053.X

Fritzell EK (1987) Gray fox and island gray fox. In 'Wild Furbearer Management and Conservation in North America'. pp. 408-420. (Ontario Trappers Association: North Bay, ON)

Fuller TK (1978) Variable home-range sizes of female gray foxes. Journal of Mammalogy 59(2), 446-449. doi:10.2307/1379941

Grinder MI, Krausman PR (2001) Home range, habitat use, and nocturnal activity of coyotes in an urban environment. The Journal of Wildlife Management 65(4), 887-898. doi:10.2307/3803038
Harris CE, Knowlton FF (2001) Differential responses of coyotes to novel stimuli in familiar and unfamiliar settings. Canadian Journal of Zoology 79, 2005-2013. doi:10.1139/Z01-163

Harrison DJ (1992) Dispersal characteristics of juvenile coyotes in Maine. The Journal of Wildlife Management 56(1), 128-138. doi:10.2307/ 3808800

Henke SE, Bryant FC (1999) Effects of coyote removal on the faunal community in western Texas. The Journal of Wildlife Management 63(4), 1066-1081. doi:10.2307/3802826

Hockman JG, Chapman JA (1983) Comparative feeding habits of red foxes (Vulpes vulpes) and gray foxes (Urocyon cinereoargenteus) in Maryland. American Midland Naturalist 110(2), 276-285. doi:10.2307/ 2425269

Kamler JF, Gipson PS (2000) Space and habitat use by resident and transient coyotes. Canadian Journal of Zoology 78(12), 2106-2111. doi:10.1139/ Z00-153

Keeley JE, Fotheringham CJ (2001) Historic fire regime in southern California shrublands. Conservation Biology 15(6), 1536-1548. doi:10.1046/J.1523-1739.2001.00097.X

Keeley JE, Zedler PH (1978) Reproduction of chaparral shrubs after fire: a comparison of sprouting and seeding strategies. American Midland Naturalist 99(1), 142-161. doi:10.2307/2424939

Keeley JE, Fotheringham CJ, Morais M (1999) Reexamining fire suppression impacts on brushland fire regimes. Science 284(5421), 1829-1832. doi:10.1126/SCIENCE.284.5421.1829

Keeley JE, Lubin D, Fotheringham CJ (2003) Fire and grazing impacts on plant diversity and alien plant invasions in the southern Sierra Nevada. Ecological Applications 13, 1355-1374. doi:10.1890/02-5002

Keeley JE, Brennan T, Pfaff AH (2008) Fire severity and ecosytem responses following crown fires in California shrublands. Ecological Applications 18(6), 1530-1546. doi:10.1890/07-0836.1

Lawrence GE (1966) Ecology of vertebrate animals in relation to chaparral fire in the Sierra Nevada foothills. Ecology 47(2), 278-291. doi:10.2307/ 1933775

Linhart SB, Knowlton FF (1975) Determining the relative abundance of coyotes by scent station lines. Wildlife Society Bulletin 3(3), 119-124.

Litvaitis JA, Sherburne JA, Bissonette JA (1986) Bobcat habitat use and home range size in relation to prey density. The Journal of Wildlife Management 50(1), 110-117. doi:10.2307/3801498

MacKenzie DI, Nichols JD, Royle JA, Pollock KH, Bailey LL, Hines JE (2006) 'Occupancy estimation and modeling: inferring patterns and dynamics of species occurrence.' (Academic Press: Burlington, MA)

Markovchick-Nicholls L, Regan HM, Deutschman DH, Widyanata A, Martin B, Noreke L, Ann Hunt T (2008) Relationships between human disturbance and wildlife land use in urban habitat fragments. Conservation Biology 22, 99-109. doi:10.1111/J.1523-1739.2007.00846.X

Neale JCC, Sacks BN (2001) Food habits and space use of gray foxes in relation to sympatric coyotes and bobcats. Canadian Journal of Zoology 79(10), 1794-1800. doi:10.1139/Z01-140

Ng SJ, Dole JW, Sauvajot RM, Riley SPD, Valone TJ (2004) Use of highway undercrossings by wildlife in southern California. Biological Conservation 115(3), 499-507. doi:10.1016/S0006-3207(03)00166-6

R Development Core Team (2010) R: a language and environment for statistical computing. (R Foundation for Statistical Computing: Vienna, Austria) Available at http://www.R-project.org [Verified 1 March 2014]

Riley SPD, Sauvajot RM, Fuller TK, York EC, Kamradt DA, Bromley C, Wayne RK (2003) Effects of urbanization and habitat fragmentation on bobcats and coyotes in southern California. Conservation Biology 17(2), 566-576. doi:10.1046/J.1523-1739.2003.01458.X

Sauvajot RM, Buechner M, Kamradt DA, Schonewald CM (1998) Patterns of human disturbance and response by small mammals and birds in chaparral near urban development. Urban Ecosystems 2(4), 279-297. doi:10.1023/A:1009588723665 
Soulé ME, Bolger DT, Alberts AC, Wrights J, Sorice M, Hill S (1988) Reconstructed dynamics of rapid extinctions of chaparral-requiring birds in urban habitat islands. Conservation Biology 2(1), 75-92. doi:10.1111/J.1523-1739.1988.TB00337.X

Syphard AD, Radeloff VC, Hawbaker TJ, Stewart SI (2009) Conservation threats due to human-caused increases in fire frequency in Mediterranean-climate ecosystems. Conservation Biology 23(3), 758-769. doi:10.1111/J.1523-1739.2009.01223.X
Western Regional Climate Center (2011) Monthly climate summary: Alpine, California. (Western Regional Climate Center: Reno, NV) Available at http://www.wrcc.dri.edu/cgi-bin/cliMAIN.pl?caalpi+sca [Verified 1 March 2014]

Windberg LA (1996) Coyote responses to visual and olfactory stimuli related to familiarity with an area. Canadian Journal of Zoology 74(12), 2248-2253. doi:10.1139/Z96-255 